\title{
Prenatal ethanol exposure induces susceptibility to premature ovarian insufficiency
}

\author{
Yuan Ni1,*, Dan Xu2,3,*, Feng Lv², Yang Wan², Guanlan Fan², Wen Zou1, Yunxi Chen1', Linguo Pei², Jing Yang1 and \\ Hui Wang2,3
}

\begin{abstract}
'Reproductive Medicine Center, Renmin Hospital of Wuhan University, Hubei Clinic Research Center for Assisted Reproductive Technology and Embryonic Development, Wuhan, China

2Department of Pharmacology, School of Basic Medical Sciences, Wuhan University, Wuhan, China

3Hubei Provincial Key Laboratory of Developmentally Originated Disease, Wuhan, China
\end{abstract}

Correspondence should be addressed to J Yang or H Wang: 13507182023@163.com or wanghui19@whu.edu.cn

*(Y Ni and $\mathrm{D}$ Xu contributed equally to this work)

\begin{abstract}
Prenatal ethanol exposure (PEE) adversely affects the offspring reproductive system. We aimed to confirm the susceptibility to premature ovarian insufficiency (POI) in female PEE offspring and elucidate its intrauterine programming mechanism. The pregnant Wistar female rats were intragastrically administered with $4 \mathrm{~g} / \mathrm{kg} \times$ day of ethanol from gestational day (GD) 9 to 20. Offspring reproductive parameters were detected on GD20, postnatal week (PW) 6 and PW12. The PEE foetuses showed a decreased number of oocytes, increased ovarian cell apoptosis and upregulated expression levels of ovarian insulin-like growth factor 1 (IGF1) signalling pathway and steroidogenic enzymes. The proportion of atretic follicles in adult rats was increased, while the number of antiMüllerian hormone-positive antral follicles was decreased. The serum oestradiol $\left(E_{2}\right)$ levels were decreased, but the follicle stimulation hormone levels were elevated. The ovarian Igf1 signalling pathway was transformed from activation during puberty to relative inhibition in adulthood, and the expression levels of ovarian steroidogenic enzymes were inhibited in adulthood. Furthermore, we treated the human granulosa cell line KGN with different ethanol concentrations $(15,30,60,120 \mathrm{mM})$ and found that the expression of IGF1 signalling pathway components, 3B-HSD and P450arom, as well as the production of $E_{2}$, was increased. After IGF1 siRNA transfection, P450arom expression and $E_{2}$ production were downregulated. These results suggest that PEE induces POI susceptibility in adult females, which may be caused by over-activation of the foetal ovarian Igf1 signalling pathway and steroidogenesis under PEE, resulting in accelerated early development of folliculogenesis and depletion of primordial follicles.
\end{abstract}

\section{Key Words}

- prenatal ethanol exposure

- premature ovarian insufficiency

- folliculogenesis

- steroidogenesis 


\section{Introduction}

Premature ovarian insufficiency (POI) refers to the clinical syndrome of ovarian activity decline in women aged less than 40 years. The clinical features of POI are menstrual disorders accompanied by hypergonadotropism and hypoestrogenism (ESHRE Guideline Group 2016), gradually progressing to premature ovarian failure (POF). POI is related to the accelerated depletion of primordial follicles, whose pool originates from the intrauterine period and could be easily disturbed by external factors, thus affecting the number of follicles throughout the reproductive lifespan (Findlay et al. 2015). Gene defects, autoimmune dysfunction and iatrogenic interventions are the known causes of POI, but $50 \%$ of the cases are not identified. A follow-up study found that adolescent girls prenatally exposed to polychlorinated biphenyls showed abnormal menstruation and elevated levels of gonadotropins (Yang et al. 2005). Rodent studies found that the intake of N-acetyl-para-aminophenol during pregnancy resulted in an irregular oestrous cycle, reduction of primordial follicles, premature absence of the corpus luteum (CL) and reduced fertility among female offspring (Arendrup et al. 2018). Female offspring rats of maternal undernutrition showed disruption in the estrous cycle, elevated gonadotropin levels, decreased oestradiol $\left(\mathrm{E}_{2}\right)$ levels and irregular ovulation (Khorram et al. 2015). Additionally, prenatal exposure to the environmental pollutant benzopyrene led to a disturbed estrous cycle, premature depleted primordial follicles and decreased fertility of female offspring mice (Vabre et al. 2017). The studies above suggest that the occurrence of POI could have a foetal origin.

Ethanol, which comprises many daily necessities, is a xenobiotic that is easily accessible to individuals. A growing number of women at childbearing age have reported long-term drinking habits, and up to $40 \%$ of women in some countries drink alcohol during pregnancy (Nykjaer et al. 2014). Thus, perinatal health problems caused by PEE are becoming a growing concern. PEE affects not only the pregnant women but also foetal development, causing spontaneous abortion, premature delivery, foetal alcohol syndrome and intrauterine growth retardation (IUGR) (Spohr et al. 1993, Nykjaer et al. 2014), with long-term impact on the offspring's reproductive function (Wilson \& Handa 1997, Dupont et al. 2012). A previous study showed that PEE can disrupt the development and function of the hypothalamic-pituitary-ovarian (HPO) axis in females, leading to dysfunction of the estrous cycle and sexual hormone secretion patterns (Gawalek \& Sliwowska 2015). Furthermore, ovarian development is impaired in IUGR foetuses, with a significant reduction in the proportion of primordial follicles (de Bruin et al. 1998). Female IUGR offspring caused by maternal undernutrition undergo POI in adult life (Khorram et al. 2015). However, scant studies have reported on whether PEE can lead to POI in IUGR offspring and the underlying mechanism of the foetal origin.

Both local factors and the neuroendocrine axis play important roles in ovarian oocyte maturation and follicular development. Among them, an important local regulatory factor is insulin-like growth factor 1 (IGF1), which not only can participate in the activation of primordial follicles and regulate the number of apoptotic follicles but can also alter the expression levels of steroidogenic enzymes through triggering the phosphatidylinositol-3-kinase/protein kinase B (PI3K/AKT) pathway (Shah et al. 2018). The HPO axis is mainly involved in the development and functional regulation of ovarian follicles after birth, because it has not been fully developed during the intrauterine period (Picut et al. 2015). Epidemiological data have shown that the serum IGF1 levels in POI women were significantly higher than those in healthy women (Hartmann et al. 1997). Animal studies have found that IGF1 can stimulate primordial follicle activation in the rat ovary (Stubbs et al. 2013), while abnormal primordial follicle maintenance is the pathophysiological basis for POI (Saatcioglu et al. 2016). Other studies have found that prepubertal ethanolexposed rats have elevated ovarian Igf1 mRNA expression but decreased protein levels, accompanied by decreased serum $\mathrm{E}_{2}$ levels (Srivastava et al. 1999). Furthermore, ethanol can affect ovarian IGF1 expression, thereby interfering with follicular development and steroid synthesis (Srivastava et al. 2007). We speculate that PEE could affect the ovarian structural and functional development of the offspring, and then increase the incidence risk of POI, which may occur by elevating the expression of the IGF1 signalling pathway.

To determine whether PEE can cause POI susceptibility in female offspring, we observed ovarian structural and functional development before and after birth in an established IUGR female rat model by PEE (Huang et al. 2018). Additionally, to elucidate the underlying mechanism, we used the human granulosa cell line from the perspective of the IGF1 signalling pathway, which would provide experimental evidence for the early prevention and reduction of the foetal origins of POI. https://joe.bioscientifica.com https://doi.org/10.1530/JOE-19-0063 (c) 2019 Society for Endocrinology Published by Bioscientifica Ltd. Printed in Great Britain 


\section{Materials and methods}

\section{Animal and treatment}

Specific pathogen-free adult Wistar female (mean body weight: $209 \pm 12 \mathrm{~g}$ ) and male (mean body weight: $258 \pm 17 \mathrm{~g}$ ) rats (certification no. 42000600002258 , license no. SCXK (E) 2012-2014) were provided by the Experimental Centre of the Hubei Medical Scientific Academy (Wuhan, China). The experiment was performed at the Centre for Animal Experiment of Wuhan University (Wuhan, China), which has been accredited by the Association for Assessment and Accreditation of Laboratory Animal Care International. All animal experimental procedures were approved by the Animal Welfare Committee of Wuhan University (License No: 14016) and were performed according to the Guidelines for the Care and Use of Laboratory Animals of the Chinese Animal Welfare Committee.

Adult female Wistar rats (F0 generation) were mated with male Wistar rats and were kept in the same room with an environmental temperature of $18-22^{\circ} \mathrm{C}$, a relative humidity of 40-60\%, a 12-h/12-h light-darkness cycle, 10-15 times air changes per hour and free access to food and water. Mating was confirmed by the presence of sperm in the morning vaginal smear, recorded as gestational day (GD) 0 . The pregnant rats were randomly divided into the control and PEE groups. From GD9 to GD20, the PEE group was intragastrically administered with $4 \mathrm{~g} / \mathrm{kg} \times$ day of ethanol (analytical pure grade; Sinopharm Chemical Reagent Co. Ltd., Shanghai, China; 10009218) (Fig. 1), while the control group was administered an equal volume of distilled water (Shen et al. 2014). An epidemiological survey showed that pregnant women who consumed 13.6 bottles of alcoholic beverages per week might cause foetal alcohol syndrome, and the ethanol intake was equivalent to $3.0-4.3 \mathrm{~g} / \mathrm{kg}$ (May et al. 2005). Related studies found that when a person intakes 3-5 bottles of beer, the average blood ethanol concentration reaches $33 \mathrm{mM}$

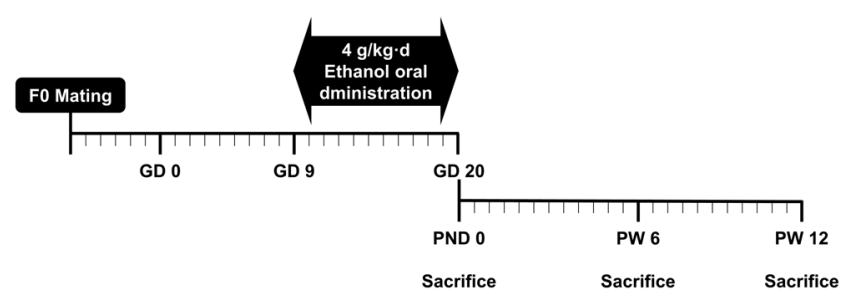

Figure 1

The schematic illustration of animal treatment. From gestational day (GD) 9-20, the pregnant Wistar rats were administrated intragastrically with $4 \mathrm{mg} / \mathrm{kg} \times$ day of ethanol. The offspring rats were killed at GD20, postnatal week (PW) 6 and PW12, respectively.
(Gohlke et al. 2005), and the blood ethanol concentration reaches approximately $20-170 \mathrm{mM}$ during moderate-tosevere alcoholism in humans (Pantazis et al. 1992). Our previous study reported that the blood concentrations of ethanol in PEE maternal and female foetal rats were 87 and $58 \mathrm{mM}$, respectively (Shen et al. 2014). Therefore, the exposure dose of ethanol used in the present study could reasonably simulate the exposure of individuals in real life.

On GD20, a subgroup of pregnant rats was anaesthetized by isoflurane (Baxter Healthcare Co., Deerfield, IL, USA; 10019-360-40) inhalation, and the foetuses were removed by caesarean section. The number of pregnant rats was 16 in each group. The IUGR diagnosis was based on two standard deviations of the foetal rat body weight lower than the mean weight of the control group (Wang et al. 2017a). The IUGR incidence was calculated based on the number of IUGR foetuses per litter compared with the total number of pups in the litter (Yu et al. 2018). Foetal blood was pooled by female grouping per dam and was centrifuged for storage. The right ovaries of five female foetuses in each group were randomly selected and fixed in freshly prepared Bouin's solution for $24 \mathrm{~h}$ and then were dehydrated with alcohol and embedded in paraffin for morphological analysis. The remaining foetal rats were collected from the litter and centrifuged for serum. The remaining foetal ovaries were quickly frozen in liquid nitrogen and stored at $-80^{\circ} \mathrm{C}$ until analysis.

The remaining pregnant rats naturally produced F1 generation rats. The number of pregnant rats was eight in each group. After weaning, all F1 females were fed with standard laboratory feed ad libitum. Two subgroups of F1 female rats were fasted overnight to avoid the effects of ingestion on the hormone levels (Yan et al. 2014, Tsoulis et al. 2016) were euthanized following isoflurane anaesthesia at postnatal week (PW) 6 or PW12 in diestrus or metestrus ( $n=8$ from eight different litters at each time point), and the ovaries, hypothalami and blood samples were collected. At PW12, the remaining female offspring were mated with normal male rats to produce F2 generation rats. The pregnancy rate, neonatal body weight, number of pups per litter, male-female ratio and litter death rate were recorded and calculated. The pregnancy rate was calculated as the number of pregnant females/number of females housed with one male $\times 100$. The litter death rate was calculated as the dead pups/number of pups per litter $\times 100$.

Vaginal patency is an important indicator of female rats entering puberty. The vaginal patency of F1 female 
rats was observed every day from the weaned day until complete opening ( $\mathrm{Lv}$ et al. 2018). The normal estrous cycle of Wistar rats is $4-5$ days (Serrano et al. 2017). The estrous cycle was examined daily at 08:00 h starting from PW10 over two cycles and was determined by cytological examination of vaginal smears (Lv et al. 2018). Four stages were used for categorization: proestrus (predominance of nucleated epithelial cells), oestrus (anucleated cornified cells), metestrus (equal portions of leukocytes, epithelial and cornified cells) and diestrus (predominance of leukocytes).

\section{Haematoxylin-eosin (HE) staining and immunohistochemistry (IHC)}

The right ovaries of five rats in each group at three time points were randomly selected for sectioning. The fixed ovaries were processed, paraffin-embedded, serially sectioned at $5 \mu \mathrm{m}$ and stained with HE. Every fifth section of the entire ovary was analysed and photographed using an Olympus AH-2 light microscope (Olympus). Only oocytes or follicles with a visible nucleus were counted to avoid multiple counts of the same one, except for atretic follicles. Healthy follicles showed no deformation of pyknotic nuclei or cell layers. Classification of the follicle stage was performed based on the granulosa cell layer morphology, and the presence or absence of an antral cavity, follicles with degeneration of oocytes and/or granulosa cells, retraction of the granulosa cell layer from oocytes or nuclear blebbing was counted as atretic follicles, as previously described (Chan et al. 2018). The number of primordial follicles, primary follicles, preantral follicles, antral follicles, atretic follicles and CL was calculated on every fifth section of the entire ovary. The thicknesses of the granulosa cell layers in antral follicles were measured in five different sections to evaluate the development of antral follicles.

IHC analysis was performed by using a DAB staining kit (GeneTech Co. Ltd., Shanghai, China; GK347011) to determine the expression levels of Ki67 (1:200; Abcam plc.; ab16667) and cleaved-caspase 3 (1:50; R\&D Systems; AF835) in foetal ovaries and anti-Müllerian hormone (AMH) (1:200; Sigma-Aldrich; SAB2108646) in ovaries at PW6 and PW12. The paraffin cross-sections of ovarian tissues were rehydrated and washed by boiling the slides in $0.01 \mathrm{M}$ citrate buffer ( $\mathrm{pH} \mathrm{6.0)}$ at $95^{\circ} \mathrm{C}$ for $10 \mathrm{~min}$, and then were incubated with primary antibody overnight at $4^{\circ} \mathrm{C}$. Negative controls were prepared by replacing the primary antibody with nonimmune rabbit immunoglobulin G. All the images were analysed using Image Pro Plus software (version 6.0; Media Cybernetics, Silver Spring, MD, USA). The intensity of Ki67 and cleaved-caspase 3 staining was determined by measuring the mean optical density in five random fields per section, and five sections from different ovaries per group were used for quantification. The evaluation of AMH-positive primary, preantral and antral follicles occurred according to the intensity and distribution of staining as previously defined (Ozcan et al. 2015), and five different fields from each section were analysed.

\section{KGN cell culture and siRNA transient transfection}

The human granulosa cell line KGN (Centre for Translational Medicine and Jiangsu Key Laboratory of Molecular Medicine, Nanjing, China) was cultured in red phenol-free Dulbecco's modified Eagle medium nutrient mixture F12 (DMEM/F12) (Gibco, Thermo Fisher Scientific; C11330500BT) containing 10\% foetal bovine serum (Gibco; 10099-141) and 0.1\% penicillin/ streptomycin at $37^{\circ} \mathrm{C}$ with $5 \% \mathrm{CO}_{2}$. The MTS cell proliferation colorimetric assay (Promega Co.; G358B) was performed to evaluate the effects of ethanol treatment on KGN cell viability according to the manufacturer's instructions. Chemically synthesized IGF1 siRNA (sense: 5'-CCUCCUCGCAUCUCUUCUATT-3'; antisense: 5'-UAGAAGAGAUGCGAGGAGGTT-3') was obtained from Suzhou GenePharma Co., Ltd. (Suzhou, China). KGN cells were seeded into six-well plates at $1 \times 10^{5}$ cells/ well 1 day before IGF1 siRNA transfection to reach the $50 \%$ confluency. After the transfection procedures were performed using Lipofectamine 3000 (Invitrogen, Thermo Fisher Scientific; L3000150) for $24 \mathrm{~h}$ according to the manufacturer's instructions, the transfection mixture medium was replaced by medium with or without ethanol $(120 \mathrm{mM})$ for $48 \mathrm{~h}$, and then the cells were harvested for further analyses. Negative control (NC) siRNA (sense: 5'-UUCUCCGAACGUGUCACGUTT-3'; antisense: 5'-ACGUGACACGUUCGGAGAATT-3') was used to assess nonspecific gene-silencing effects.

\section{Quantification of hormone levels}

The foetal serum levels of $E_{2}$ were measured using an ELISA kit (R\&D Systems; KGE014; minimum detectable concentration: $2.14 \mathrm{pg} / \mathrm{mL}$; intra-assay coefficient of variation (CV) <6.0\%; inter-assay $\mathrm{CV} \quad<7.1 \%$ ). The radioimmunoassay (RIA) kits for rat $E_{2}$, folliclestimulating hormone (FSH) and luteinizing hormone (LH) were purchased from Beijing North Institute of 
Biological Technology (Beijing, China). The levels of $E_{2}$ in the serum of postnatal rats and supernatant of KGN cells were detected by RIA (sensitivity $<5 \mathrm{pg} / \mathrm{mL}$; intra-assay CV $<10 \%$; inter-assay CV $<15 \%$ ). The serum levels of FSH and LH in the postnatal rats were measured by RIA (sensitivity $<1.0 \mathrm{mIU} / \mathrm{mL}$; intra-assay $\mathrm{CV}<10 \%$; inter-assay $\mathrm{CV}$ $<15 \%)$. The Rat AMH ELISA kit (Cusabio Biotech Co. Ltd., Wuhan, China; CSB-E11162r) was used to quantify the serum levels (detection range: $0.2 \sim 15 \mathrm{ng} / \mathrm{mL}$; intra-assay $\mathrm{CV}<15 \%$; inter-assay $\mathrm{CV}<15 \%)$. All test procedures were performed following the manufacturer's instructions.

\section{RNA isolation and real-time quantitative PCR (RT-qPCR)}

Total RNA extraction from the ovary, hypothalamic and KGN cells was performed using TRIzol reagent (Invitrogen Co.; 15596018) and following the manufacturer's protocol. The reverse transcription reagent kit used was purchased from TaKaRa Biotech Co. Ltd. (Beijing, China; RR047A). The tissues obtained from each littermate were pooled for homogenization as one sample. The total RNA quantity and quality were measured using the NanoDrop 2000 system (Bio-Rad Co.), and the total RNA concentration was adjusted to $1000 \mathrm{ng} / \mu \mathrm{L}$. Complementary DNA was synthesized from $1 \mu \mathrm{g}$ of total RNA according to the kit protocol and was stored at $-20^{\circ} \mathrm{C}$ for testing. Primers were designed using Primer Premier 5.0 (PREMIER Biosoft International, Palo Alto, CA, USA), and the sequences were queried using the NCBI BLAST database (Supplementary Table 1 , see section on supplementary data given at the end of this article). All the primers were synthesized by Sangon Biotech Co. Ltd. (Shanghai, China). SYBR Green dye was purchased from Applied Biosystems (ABI; 4472908). Each PCR was performed in a $10 \mu \mathrm{L}$ volume using the ABI StepOne RT-PCR Thermal Cycler (Thermo Fisher Scientific). To more accurately quantify the gene transcripts, the mRNA level of the housekeeping gene GAPDH was detected and used as the quantitative control. The transcript levels of the target genes at each time point were expressed relative to the GAPDH transcript levels. Each sample was normalized against the GAPDH mRNA level.

\section{Western blotting}

Protein was extracted from the KGN cells using RIPA buffer (Applygen Technologies Inc, Beijing, China; C1053) containing protease inhibitors (Complete Mini; Roche; 11836153001) and phosphatase inhibitors
(PhosSTOP; Roche; 04906845001). The protein concentrations were quantified using the BCA Protein Assay Kit (Beyotime; P0011). Protein $(15 \mu \mathrm{g})$ extracts were separated by $12 \%$ SDS-PAGE and were transferred to PVDF membranes (Immobilon; Merck Millipore; IPVH00010) according to the manufacturer's instructions. The membranes were blocked with 5\% nonfat dried milk for $1 \mathrm{~h}$ and were then incubated with primary antibodies at $4^{\circ} \mathrm{C}$ overnight. The following antibodies were used: antiGAPDH (1:5000; ABclonal; AC002), anti-IGF1 (1:1000; Novus Biologicals; SPM406), anti-AKT (1:1000; CST; 4691s) and anti-phospho-AKT (Ser473) (1:2000; CST; 4060). After incubation and washing, the membranes were incubated with secondary antibodies (anti-mouse and anti-rabbit conjugated with horseradish peroxidase) at a 1:5000 dilution for $1 \mathrm{~h}$ and were detected using an enhanced chemiluminescent detection kit (Bridgen, Beijing, China; D046). Densitometric analyses were performed using ImageJ software (National Institutes of Health).

\section{Statistical analysis}

Quantitative data were expressed as the mean \pm standard error of the mean (S.E.M.). All statistical analyses were performed using the SPSS 20.0 statistics package (SPSS) and Prism 6.0 (GraphPad Software). The mean weights of each litter were used for the statistical analysis as for the weight of the foetuses. The IUGR incidence of each litter was analysed using the arcsine square root transformed before the $t$-test evaluations. The mean values were compared using Student $t$-test or one-way ANOVA followed by the post hoc Dunnett's-t-test. The threshold for significance was set as $P<0.05$.

\section{Results}

\section{Animal experiments}

\section{Effects of PEE on body weight and ovarian morphology of foetal rats}

We observed changes in the body weight and ovarian morphology of female foetal rats on GD20. Compared with the control group, PEE foetuses had a lower body weight and a higher IUGR incidence $(P<0.01$, Fig. 2A and $\mathrm{B})$. HE staining of the foetal ovary in the PEE group showed a decreased number of oocytes per unit area $\left(10,000 \mu \mathrm{m}^{2}\right)(P<0.05$, Fig. $2 \mathrm{C}$ and $\mathrm{D})$. IHC results showed that the mean optical density of positively stained cells of Ki67 in the foetal ovary was reduced $(P<0.05$, Fig. $2 \mathrm{E}$ and $\mathrm{F}$ ), while the cleaved-caspase 3 was increased 
A

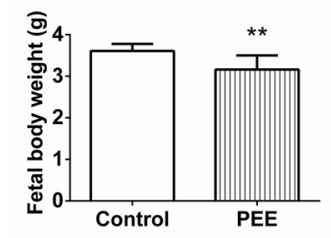

C

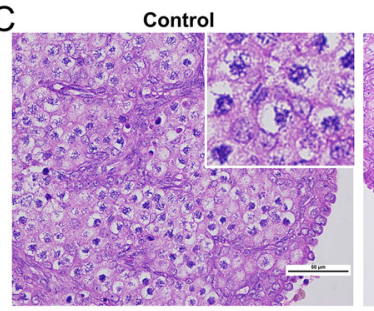

E

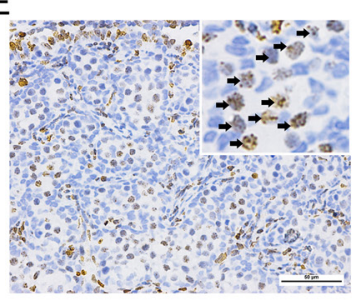

G

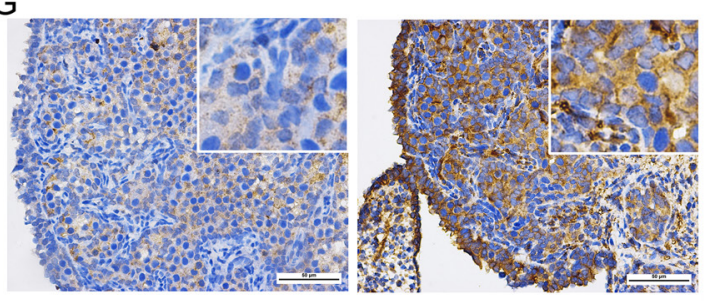

B
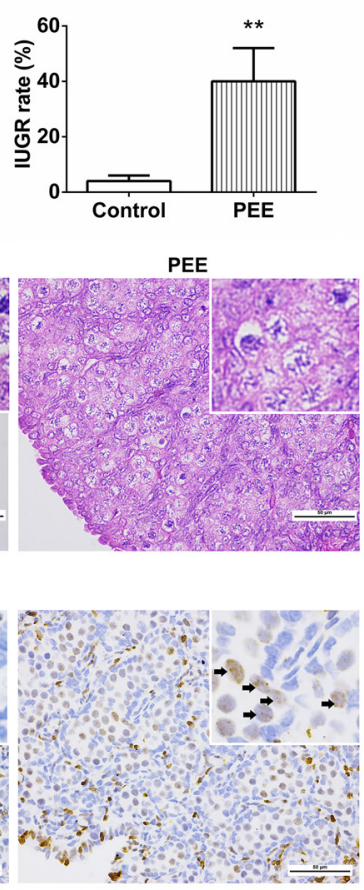

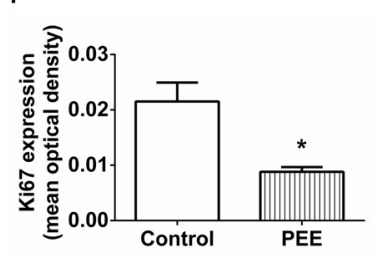

$\mathrm{H}$

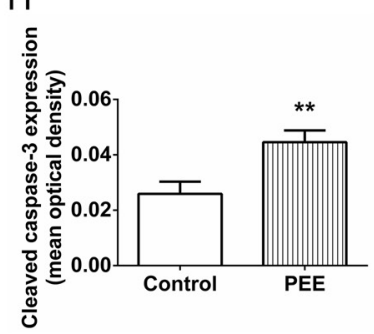

\section{Figure 2}

Effects of prenatal ethanol exposure (PEE) on body size, body weight and ovarian morphology in female foetal rats. (A and B) Foetal bodyweight and intrauterine growth restriction (IUGR) incidence. Mean \pm S.E.M., $n=12$. (C) Foetal ovary morphology (haematoxylin-eosin staining, $\mathrm{HE}$ $\times 400$ ); (D) Number of oocytes per unit area $\left(10,000 \mu \mathrm{m}^{2}\right) ;(E$ and $\mathrm{G})$ Immunohistochemistry of Ki67 and cleaved-caspase 3

(immunohistochemistry, IHC $\times 400$ ) in the foetal ovary; $(\mathrm{F}$ and $\mathrm{H})$ mean optical density of nuclei-stained cells with Ki67 and cleaved-caspase 3 protein expression. Mean \pm S.E.M., $n=5$. $* P<0.05$, $\star \star P<0.01$ vs control. A full colour version of this figure is available at https://doi.org/10.1530/ JOE-19-0063.
$(P<0.01$, Fig. $2 \mathrm{G}$ and $\mathrm{H})$. These results indicate that PEE can cause low birth weight and a high IUGR incidence in foetal rats and abnormal morphological development of the ovary in the IUGR offspring, characterized by abnormal folliculogenesis, reduced cell proliferation and increased apoptosis.

\section{Effects of PEE on the levels of ovarian IGF1 signalling pathway components, steroidogenic enzymes and $E_{2}$ in foetal rats}

To investigate the mechanism underlying the foetal origin of foetal ovarian development abnormalities caused by PEE, we examined the expression of ovarian IGF1 signalling pathway components, steroidogenic enzymes and serum $\mathrm{E}_{2}$ levels in foetal rats. Compared with the control, the mRNA expression level of Igf1 was significantly upregulated $(P<0.01)$, and the expression levels of its receptor Igf1r and downstream gene Akt2 were also increased in the PEE female foetuses $(P<0.01$, Fig. 3A). Furthermore, the mRNA expression levels of $3 \beta-H S D$ and $17 \beta$-HSD1 were increased $(P<0.05)$ and that of $17 \beta$-HSD2 was decreased $(P<0.01$, Fig. $3 \mathrm{~B})$, but no significant change was found in the foetal serum $\mathrm{E}_{2}$ levels in the PEE group $(P<0.05$, Fig. $3 C)$. These data suggest that the foetal ovarian IGF1 signalling pathway and steroid synthetic function are activated by PEE.

\section{Effects of PEE on the body weight, estrous cycle and reproductive function of offspring rats after birth}

To determine whether the ovarian development abnormalities caused by PEE will persist after birth and have a programming effect, we observed the body weight of female offspring rats at different time points after birth. Compared with the control, the birth weight of PEE group was significantly lower $(P<0.01)$, while the body weight was increased at PW6 and decreased at PW12 $(P<0.01$, Fig. 4A). The body weight gain rate of the PEE group also increased significantly at PW6 ( $P<0.01$, Fig. 4B). These results suggest that the female offspring of PEE 

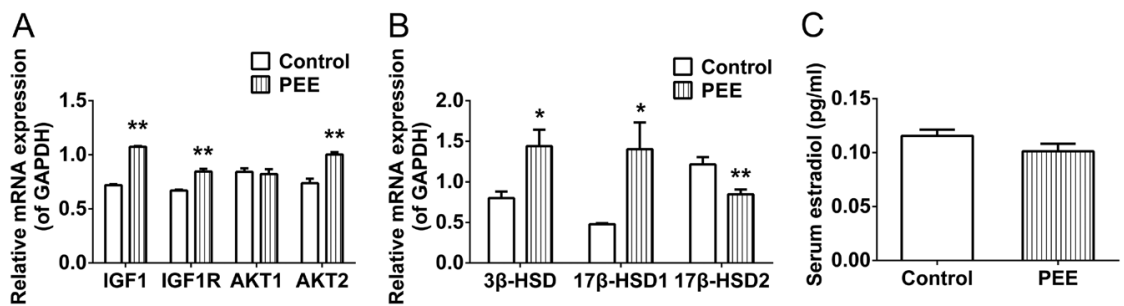

\section{Figure 3}

Effects of prenatal ethanol exposure (PEE) on the levels of ovarian insulin-like growth factor 1 (IGF1) signalling pathway-related genes, steroidogenic enzymes and serum oestradiol $\left(E_{2}\right)$ concentration in female foetal rats. (A) mRNA expression of ovarian IGF1 signalling pathway-related genes; (B) mRNA expression of ovarian steroidogenic enzymes; (C) serum $E_{2}$ concentration. Mean \pm S.E.M., $n=8$ for mRNA expression ( 6 pairs of foetal ovaries from two litters were pooled for homogenization into one sample); $n=4$ for $E_{2}$ concentration (blood from 3 to 4 litters were pooled into one sample). ${ }^{*}<0.05$,

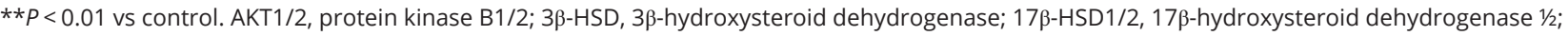
GAPDH, glyceraldehyde 3-phosphate dehydrogenase; IGF1R, insulin-like growth factor 1 receptor.

exhibit catch-up growth in the early postnatal period (especially at PW6).

We observed the estrous cycle of female offspring beginning from PW10. Compared with the control, the oestrus period of PEE was significantly shortened $(P<0.05$, Fig. $4 \mathrm{C})$; however, with the onset of puberty, the time of vaginal patency showed no significant difference (Supplementary Fig. 2A). We also tested the fertility of adult female offspring. The results showed no significant difference in the pregnancy rate of F1 females and neonatal body weight, number of pups per litter, male-female ratio and litter death rate of F2 females (Supplementary Fig. 2E, F, G, H and I). These data suggest that PEE can cause irregular cycles in the female offspring, but has no significant effect on the onset of puberty and reproductive function.

\section{Effects of PEE on ovarian morphology and follicular development of offspring rats after birth}

We continued to observe ovarian development from puberty to adulthood. Compared with the control, PEE showed no significant changes in the ovarian weight at PW6 and PW12 (Fig. 5A), while the ovary index increased significantly at PW12 $(P<0.05$, Fig. 5B), suggesting that the ovarian weight of PEE female offspring showed catch-up growth after birth and the ovarian growth was faster than the overall development of the body.
Furthermore, we observed changes in ovarian morphology. Although the total numbers of follicles and the numbers of CL at PW6 and PW12 ovary were not significantly different from those of the control (Supplementary Fig. 2B and C), the proportion of atretic follicles at PW12 was increased $(P<0.01$, Fig. 5C). Additionally, the thickness of granulosa cells of the antral follicle at PW6 was significantly thinner $(P<0.05$, Fig. 5D and E), and this difference persisted at PW12 $(P<0.05$, Fig. 5F and G). The serum AMH levels were similar between groups at PW6 and PW12 (Supplementary Fig. 2D), and the IHC results showed that the numbers of follicles positive for AMH were similar at PW6 (Fig. 5H and I), but the number of AMH-positive antral follicles was reduced significantly at PW12 $(P<0.05$, Fig. 5J and K). These results suggest that PEE affects the development of the follicle structure and ovarian reserve.

\section{Effects of PEE on the ovarian IGF1 signalling pathway and $E_{2}$ synthesis in offspring after birth}

To investigate the mechanism of abnormal ovarian development in the PEE female offspring rats, we examined the levels of ovarian IGF1 signalling pathway components, steroidogenic enzymes and serum $\mathrm{E}_{2}$ levels in rats after birth. The mRNA expression of IGF1 signalling pathway components (including Igf1r, Akt1 and Akt2) in the PEE group increased significantly at PW6 $(P<0.01$, Fig. 6A) but did not change at PW12. The mRNA
A
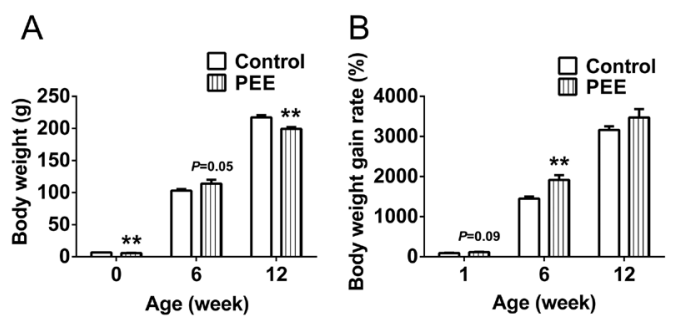

C

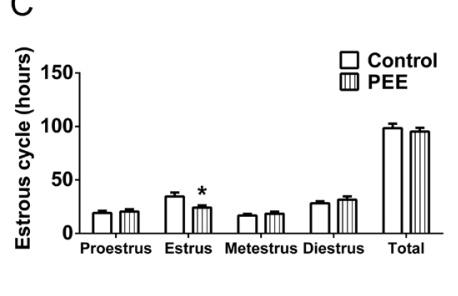

\section{Figure 4}

Effects of prenatal ethanol exposure (PEE) on the body weight, body weight gain rate and estrous cycle in female offspring rats after birth. (A) Body weight; (B) body weight gain rate and (C) oestrous cycle. Mean \pm s.E.M., $n=8 .{ }^{*} P<0.05, * \star P<0.01$ vs control. 
A

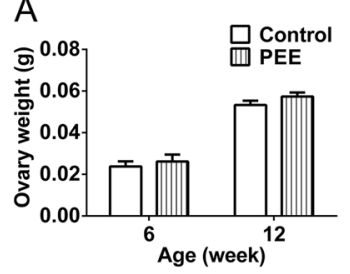

C

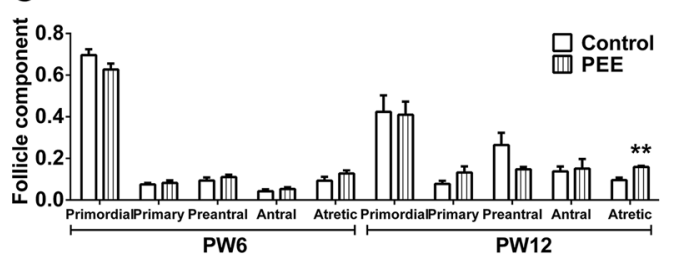

D

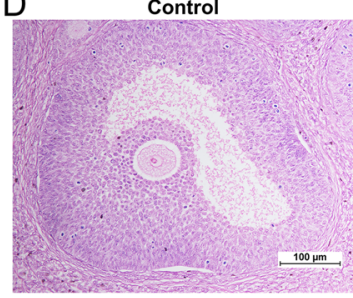

$\mathrm{F}$

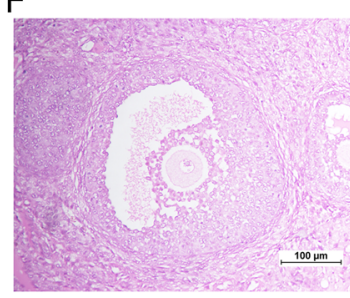

$\mathrm{H}$

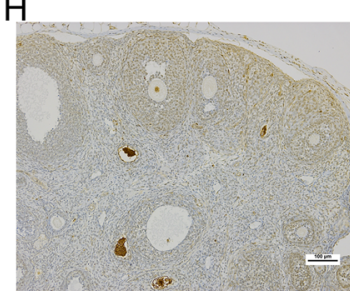

$\mathrm{J}$

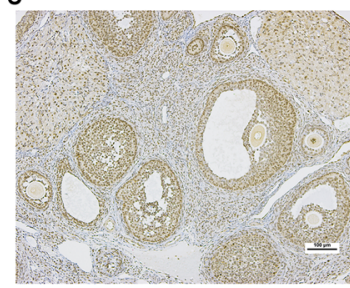

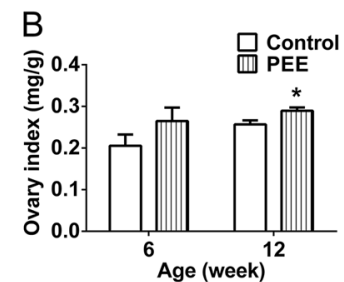

$\square$ Control
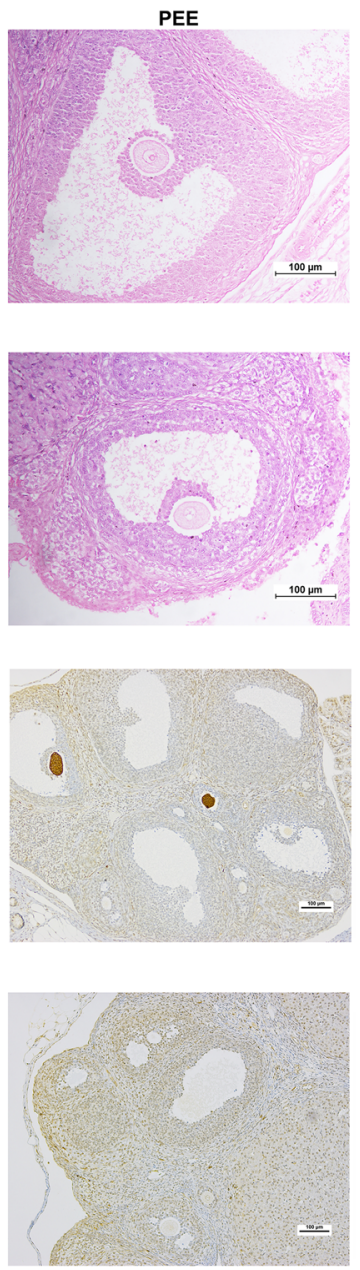

$\rightarrow$

E

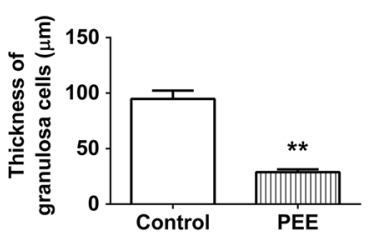

G

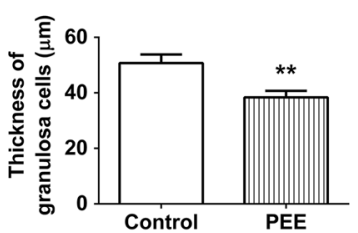

I

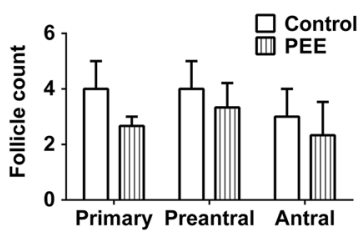

K

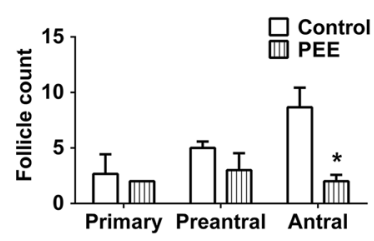

\section{Figure 5}

Effects of prenatal ethanol exposure (PEE) on ovary weight, ovary weight index, ovarian histological morphology in female offspring rats after birth. (A) Ovary weight; (B) ovary index; (C) cross-section follicle component at postnatal week (PW) 6 and PW12; (D and F) antral follicle at PW6 and PW12 (haematoxylin-eosin staining, HE $\times 400)$; ( $E$ and $G$ ) thickness of granulosa cells of rat antral follicle at PW6 and PW12; ( $\mathrm{H}$ and $\mathrm{J})$

immunohistochemistry of rat ovary anti-Müllerian hormone (AMH) at PW6 and PW12

(immunohistochemistry, IHC $\times 200$ ); (I and K) number of follicles positive for rat ovary $\mathrm{AMH}$ at PW6 and PW12. Mean \pm S.E.M., $n=5$ for HE and IHC. $* P<0.05, * * P<0.01$ vs control. A full colour version of this figure is available at https://doi. org/10.1530/JOE-19-0063. expression levels of $S f-1$ and $P 450 c 17$ were increased at PW6 $(P<0.01, P<0.05)$; however, the expression levels of ovarian steroidogenic enzyme-related genes at PW12, including StAR, 3 $\beta$-HSD, 17 $\beta$-HSD1/2, and P450arom, were inhibited $(P<0.01, P<0.05)$, while only the expression level of $P 450 \mathrm{scc}$ was increased $(P<0.05$, Fig. 6B). The serum $E_{2}$ level of the PEE group showed no change at
PW6 but was much lower than that of the control at PW12 $(P<0.05$, Fig. 6C). These results suggest that the expression of IGF1 signalling pathway components and steroidogenic enzymes in the ovary of PEE female offspring rats is increased during puberty (PW6), but the oestrogen synthetic function is significantly inhibited in adulthood (PW12). 


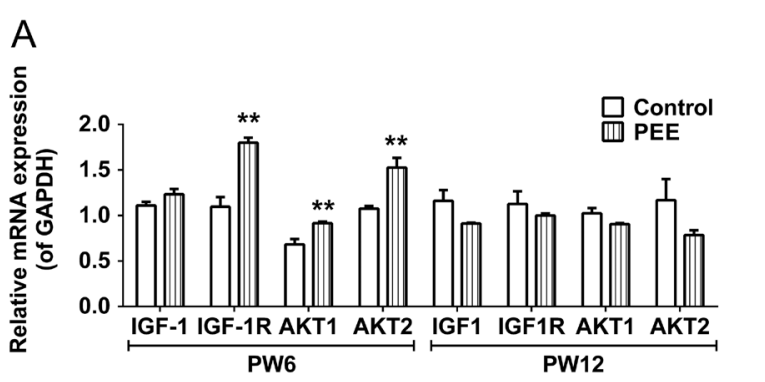

$\mathrm{B}$

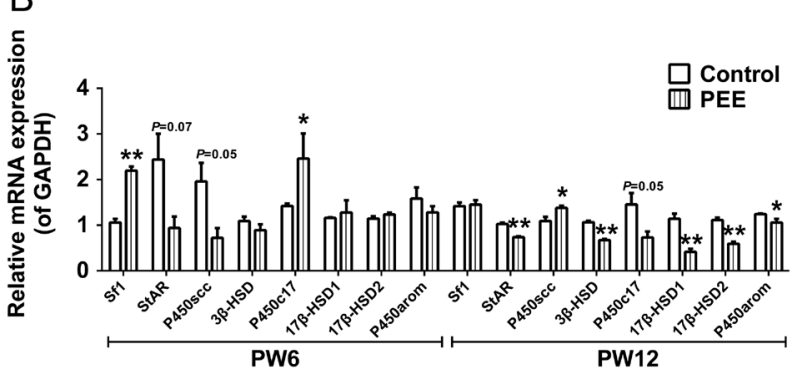

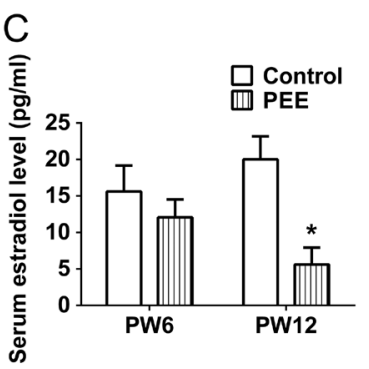

Figure 6

Effects of prenatal ethanol exposure (PEE) on the ovarian insulin-like growth factor 1 (IGF1) signalling pathway-related genes, steroidogenic enzymes and serum oestradiol $\left(E_{2}\right)$ concentration in female offspring rats after birth. (A) mRNA expression of ovarian IGF1 signalling pathwayrelated genes; (B) mRNA expression of ovarian steroidogenic enzymes; (C) serum $E_{2}$ concentration. Mean \pm S.E.M., $n=8$. $* P<0.05$, $\star \star P<0.01$ vs control. $17 \beta-$ HSD $1 / 2$, $17 \beta$-hydroxysteroid dehydrogenase type 1/2;

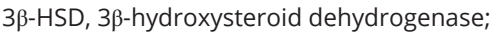
AKT1/2, protein kinase B1/2; GAPDH, glyceraldehyde 3-phosphate dehydrogenase IGF1R, insulin-like growth factor 1 receptor; P450arom, cytochrome P450 aromatase; P450c17, steroid 17-hydroxylase; P450scc, cytochrome P450 cholesterol side chain cleavage; Sf-1, steroidogenic factor 1; StAR, steroidogenic acute regulatory protein.

\section{Effects of PEE on the HPO axis of offspring rats after birth}

We also observed the changes in the HPO axis in the female offspring rats after birth following PEE. Compared with the control, the mRNA expression levels of GnRH and Kiss 1 in the hypothalamus of PEE offspring rats did not change significantly at PW6 and PW12 (Fig. 7A). The serum LH levels were similar at PW6 and PW12 (Fig. 7C), but the serum FSH level and FSH/LH ratio were increased significantly at PW12 $(P<0.05, P<0.01$, Fig. 7B and D), accompanied by decreased downstream ovarian Fshr mRNA and $\mathrm{E}_{2}$ levels $(P<0.01, P<0.05$, Figs $6 \mathrm{C}$ and $7 \mathrm{~A})$. These results suggest that the HPO axis of female PEE offspring is activated in adulthood and participates in the negative feedback regulation of ovarian steroid hormone synthesis, resulting in excessive release of FSH secreted by the anterior pituitary gland.

\section{In vitro experiments}

\section{Effects of ethanol on KGN cell viability and $E_{2}$ production}

To demonstrate the direct toxic effects of ethanol on ovarian granulosa cells, we performed in vitro experiments using the human KGN cell line. According to our previous study, the blood concentrations of PEE maternal and female foetal rats were 87 and $58 \mathrm{mM}$, respectively (Shen et al. 2014). Therefore, we treated the KGN cells with 15 , 30,60 and $120 \mathrm{mM}$ ethanol. The MTS results showed that no cytotoxic effect in each concentration group after $72 \mathrm{~h}$
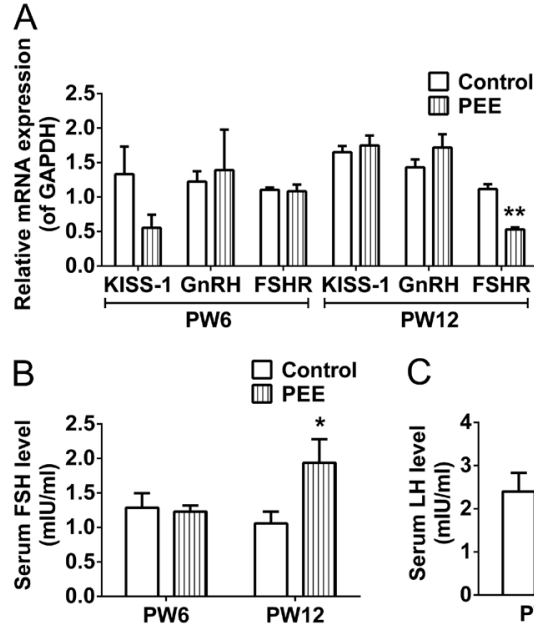

C
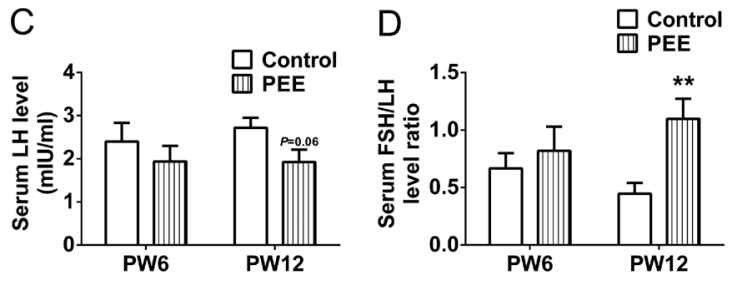

Figure 7

Effects of prenatal ethanol exposure (PEE) on the hypothalamic-pituitary-ovarian (HPO) axis in female offspring rats after birth. (A) mRNA expression of HPO axis-related genes; (B, $C$ and $D)$ Serum follicle-stimulating hormone (FSH) and luteinizing hormone $(\mathrm{LH})$ concentration, as well as $\mathrm{FSH} / \mathrm{LH}$ concentration ratio. Mean \pm S.E.M., $n=8$. $\star P<0.05, * \star P<0.01$ vs control. FSHR, folliclestimulating hormone receptor; GAPDH, glyceraldehyde 3-phosphate dehydrogenase; $\mathrm{GnRH}$, gonadotropin releasing hormone; KISS-1, Kisspeptin-1. 

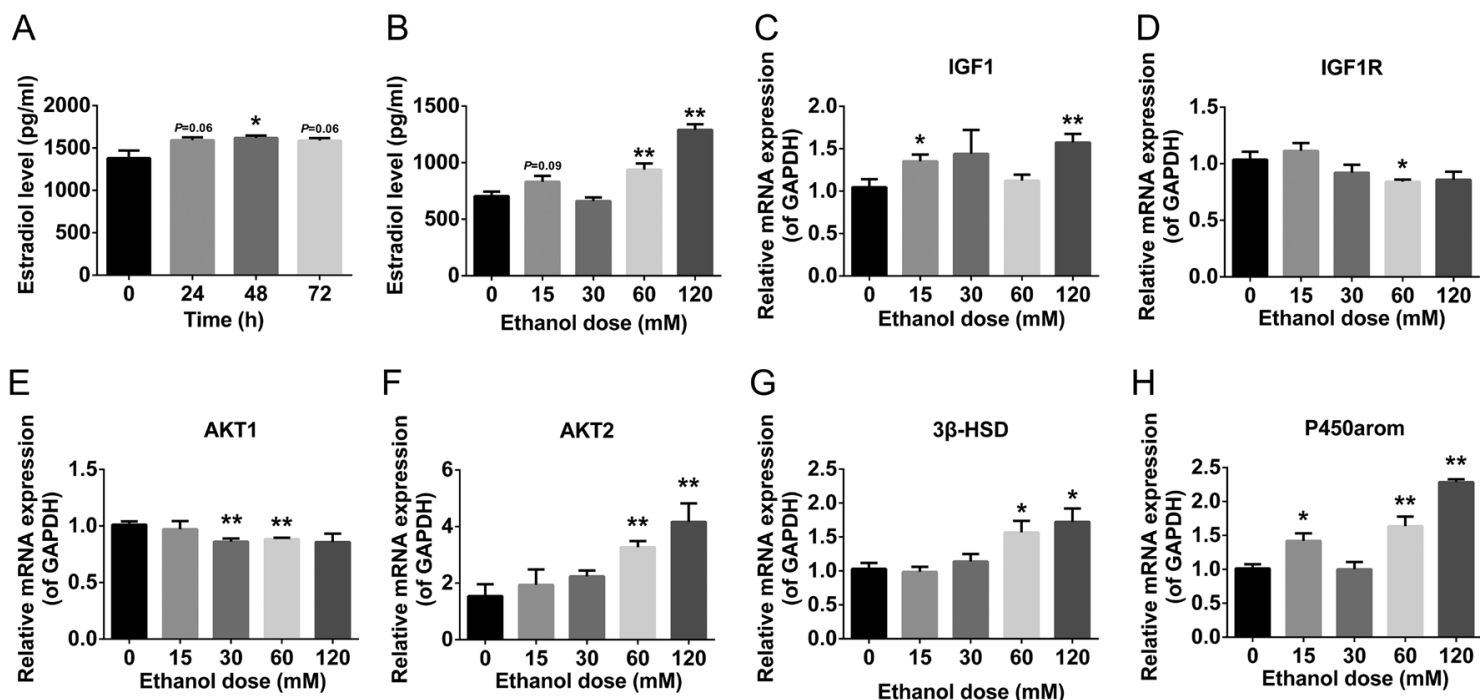

$\mathrm{F}$
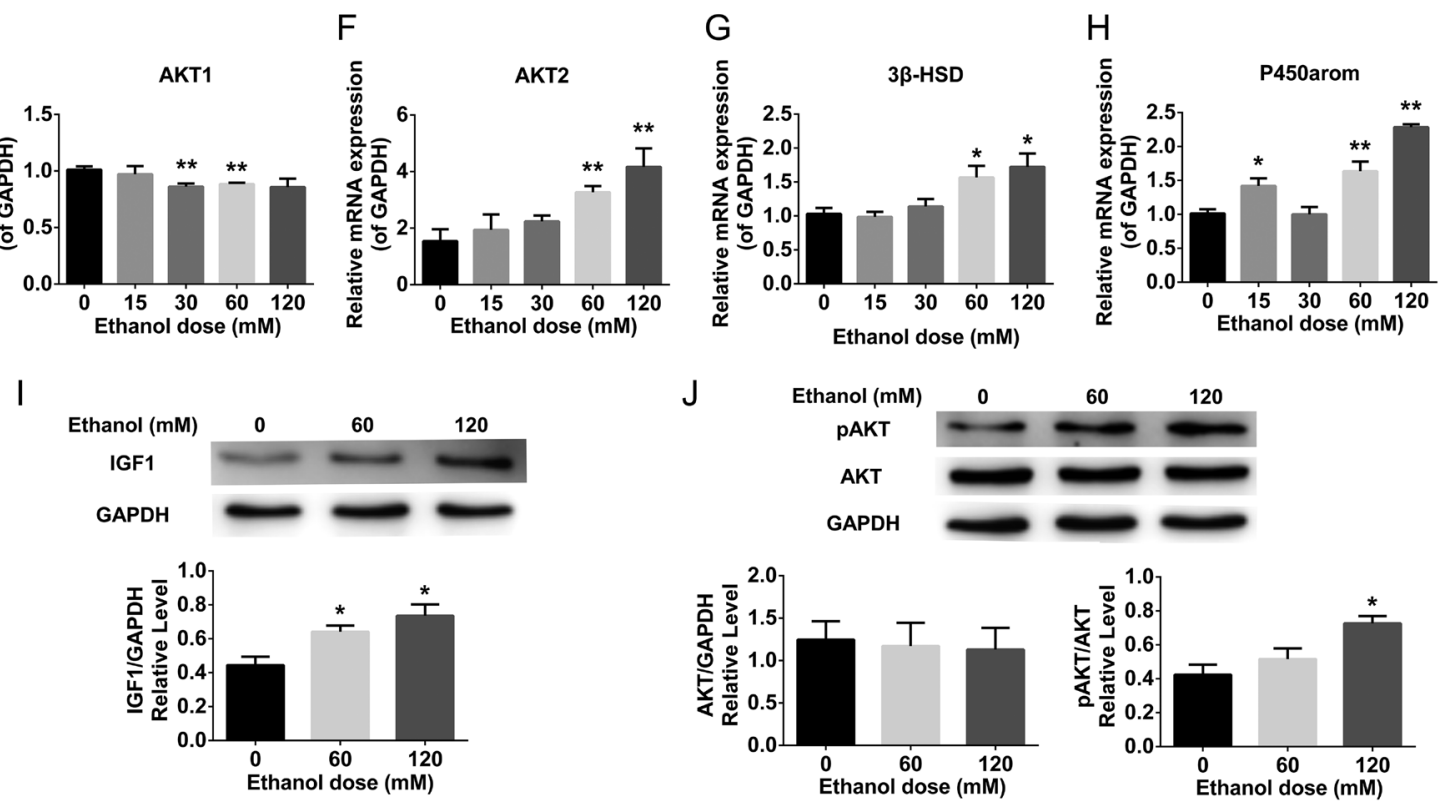

Figure 8

Effects of ethanol exposure on cell supernatant oestradiol $\left(E_{2}\right)$ concentration, insulin-like growth factor 1 (IGF1) signalling pathway-related genes and steroidogenic enzymes in KGN cells. ( $A$ and $B$ ) $E_{2}$ concentration in cell supernatant; (C, D, E and F) mRNA expression of IGF1 signalling pathway-related genes; $(\mathrm{G}$ and H) mRNA expression of 3 $\beta$-HSD and P450arom; (I and J) protein expression of IGF1 signalling pathway-related genes. Mean \pm S.E.M., $n=6$ for

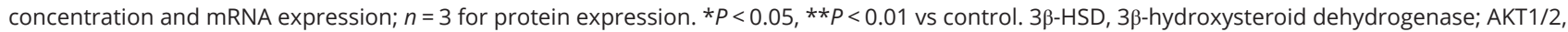
protein kinase B1/2; GAPDH, glyceraldehyde 3-phosphate dehydrogenase; IGF1R, insulin-like growth factor 1 receptor; P450arom, cytochrome P450 aromatase; PAKT, phospho-AKT.

of ethanol treatment (data not shown). Furthermore, the $\mathrm{E}_{2}$ levels increased or presented an increased trend after ethanol treatment at $120 \mathrm{mM}$ for 24,48 and $72 \mathrm{~h}(P<0.05$, $P=0.06$, Fig. 8A). After treatment with four different concentrations of ethanol $(15,30,60,120 \mathrm{mM})$ for $48 \mathrm{~h}$, the $\mathrm{E}_{2}$ levels of the 60- and 120-mM ethanol groups were significantly elevated $(P<0.01$, Fig. $8 \mathrm{~B})$ in a concentrationdependent manner. The results suggest that ethanol treatment does not affect the activity of KGN cells but promotes the $\mathrm{E}_{2}$ synthesis.

\section{Effects of ethanol on the IGF1 signalling pathway and steroidogenic enzymes in the KGN cells}

We further explored the effects of ethanol treatment on KGN cells for $48 \mathrm{~h}$ and found that the mRNA expression of IGF1 in the 15- and 120-mM ethanol groups $(P<0.05, P<0.01$, Fig. $8 C)$, as well as that of $A K T 2(P<0.01$, Fig. $8 F)$ and $3 \beta-H S D$ $(P<0.05$, Fig. 8G) in the $60-$ and $120-\mathrm{mM}$ ethanol groups,

(C) 2019 Society for Endocrinology Published by Bioscientifica Ltd. Printed in Great Britain was increased, and the mRNA expression levels of P450arom in the 15-, 60- and $120-\mathrm{mM}$ ethanol groups were also increased compared with that of the control $(P<0.05$, $P<0.01$, Fig. $8 \mathrm{H})$. Next, the expression levels of IGF1 signalling pathway components and several steroidogenic enzymes showed concentration-dependent upregulation, corresponding to the above change in the $\mathrm{E}_{2}$ levels (Fig. $8 B)$. The protein expression of IGF1 in the 60- and 120-mM ethanol groups $(P<0.05$, Fig. 8I) and pAKT/AKT in the 120 -mM ethanol group $(P<0.05$, Fig. $8 \mathrm{~J})$ were significantly elevated. These results suggest that ethanol can upregulate the IGF1 signalling pathway and $\mathrm{E}_{2}$ synthesis in KGN cells.

\section{Effects of ethanol on the IGF1 signalling pathway and $E_{\mathbf{2}}$ synthesis in KGN cells transfected with IGF1 siRNA}

We used IGF1 siRNA to verify whether IGF1 was involved in the KGN cell dysfunction by ethanol exposure. The results showed that the IGF1 mRNA and protein 
expression levels were significantly decreased after IGF1 siRNA treatment compared with those in the NC siRNA group $(P<0.01$, Fig. $9 \mathrm{~A}$ and $\mathrm{G})$, comfirming the silencing efficiency. Additionally, the mRNA expression of downstream AKT2 in the IGF1 siRNA plus ethanol group was significantly lower than that of the NC siRNA plus ethanol group $(P<0.01$, Fig. 9D). The protein expression levels of IGF1 and pAKT/AKT in the IGF1 siRNA plus ethanol group were significantly lower than those of the NC siRNA plus ethanol group $(P<0.01$, Fig. 9G and $\mathrm{H})$. The mRNA expression of $3 \beta$-HSD and P450arom, as well as the $\mathrm{E}_{2}$ levels of the IGF1 siRNA plus ethanol group, were lower than those of the NC siRNA plus ethanol treatment group $(P<0.01, P<0.05$, Fig. $9 \mathrm{E}, \mathrm{F}$ and $\mathrm{I})$. These results suggest that IGF1 participates in the ethanol-induced activation of the IGF1 signalling pathway and steroid synthetic function in KGN cells.

\section{Discussion}

\section{Susceptibility to POI induced by PEE}

The features of the POI animal model include the following (Zhang et al. 2016, Vabre et al. 2017): (1) a shortened, prolonged or stopped estrous cycle (Bernstein et al. 2014, Cruz et al. 2017); (2) increased FSH and/or LH levels, and decreased $\mathrm{E}_{2}$ levels; (3) a decreased number of ovarian follicles and $\mathrm{CL}$, a decreased ovulation rate and increased
A
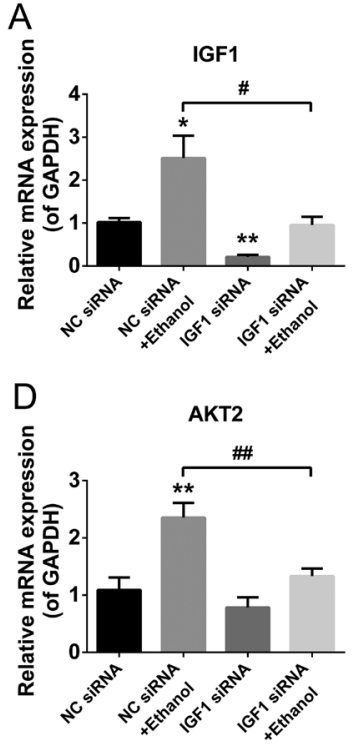

G
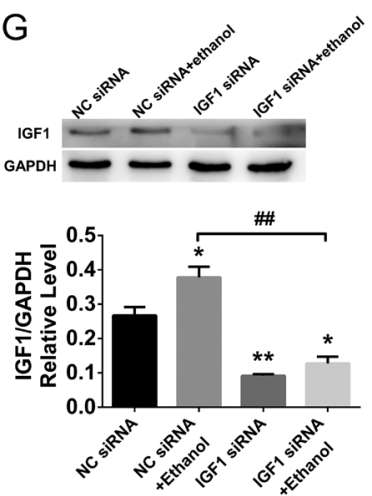
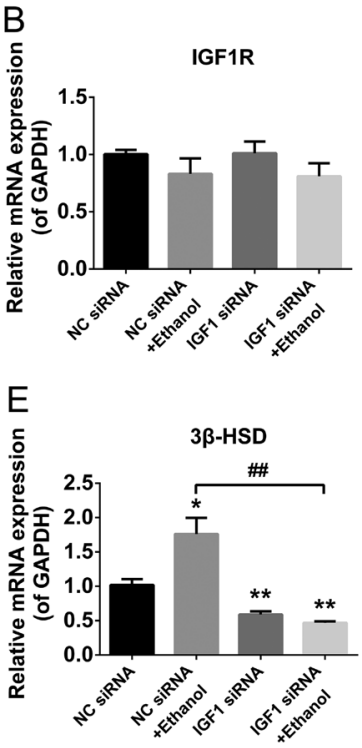

$\mathrm{H}$
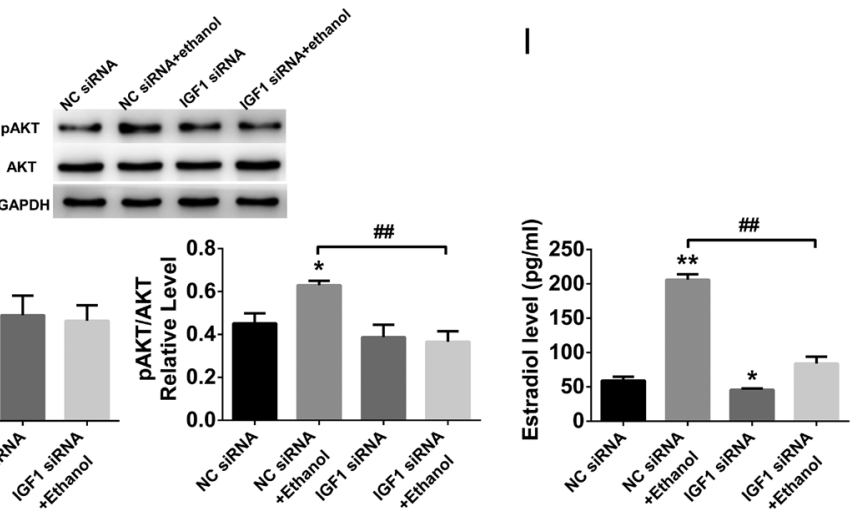

Figure 9

Effects of $120 \mathrm{mM}$ ethanol exposure for $48 \mathrm{~h}$ on the insulin-like growth factor 1 (IGF1) signalling pathway-related genes and steroidogenic enzymes in KGN cells transfected with IGF1 siRNA. (A, B, C and D) mRNA expression of IGF1 signalling pathway-related genes; (E and F) mRNA expression of $3 \beta$-HSD and P450arom; (G and $\mathrm{H}$ ) protein expression of IGF1 signalling pathway-related genes; (I) Oestradiol ( $\left.E_{2}\right)$ concentration in cell supernatant. Mean \pm S.E.M., $n=6$ for concentration and mRNA expression; $n=3$ for protein expression. $* P<0.05, * \star P<0.01$ vs negative control (NC); $P^{2}<0.05$, \#\# $P<0.01$ vs

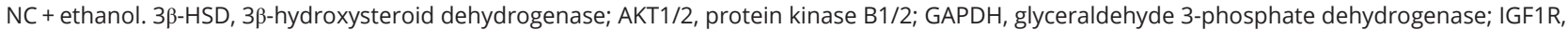
insulin-like growth factor 1 receptor; P450arom, cytochrome P450 aromatase; pAKT, phospho-AKT. 
atretic follicles and (4) declined fertility. Among them, the sex hormone levels, ovarian structure and function are the core indicators of the establishment of the POI model (Zhang et al. 2016). In this study, we observed the following changes in PEE female offspring rats: (1) estrous cycle disorder, characterized by a shortened oestrus; (2) an elevated serum FSH with decreased $\mathrm{E}_{2}$ in adulthood; (3) a significantly increased proportion of atretic follicles in the ovary in adulthood. Thus, our results suggest that female PEE offspring have features similar to POI after birth.

\section{Over-activation of the IGF1 signalling pathway mediates PEE-induced foetal ovarian development abnormalities}

It was found that exposure to chromium in the middle and late stages of pregnancy increased the apoptosis of germ cells in female offspring, reduced the number of oocytes, and accelerated the breakdown of the germ cell nests and formation of primordial follicles, leading to POI (Sivakumar et al. 2014). The time point GD20 selected in this study was the time that the rats were in the process of primordial follicle formation, and the results showed that the local structure of the PEE foetal ovary shows a decreased number of oocytes, the expression of Ki67 reflecting cell proliferation is decreased, and the expression of cleavedcaspase 3 reflecting the cell apoptosis is increased.

Studies have shown that IGF1 is directly involved in ovarian folliculogenesis (Silva et al. 2009) and initiates the transformation of primordial follicles into primary follicles (Stubbs et al. 2013). In the present study, the IGF1 signalling pathway was over-activated, speculating that its activation accelerated the normal follicular growth rate. Related studies have also suggested that the establishment of follicular pool at birth in rats would be disturbed by a detrimental maternal environment (Guzman et al. 2014). Exposure to monoethylhexyl phthalate in mice during pregnancy causes early ovarian ageing in the F1 generation due to accelerated follicular recruitment, resulting in depletion of the primordial follicle pool (Moyer \& Hixon 2012, Zhang et al. 2015). It was reported that the PI3K/AKT signalling pathway is involved in the regulation of primordial follicle survival and recruitment, and activation of this pathway leads to oocyte development and follicle activation (Zheng et al. 2012). In the studies of other organ development (such as the eyeball), increased exogenous IGF1 accelerates visual cortical development, promoting the early maturity of visual acuity (Ciucci et al. 2007). These results suggest that PEE causes abnormal development of female offspring and interferes with the initial stage of folliculogenesis, which might be caused by excessive activation of the IGF1 signalling pathway.

IGF1 not only participates in follicular development but also promotes the expression of steroidogenic enzymes and affects ovarian oestrogen synthesis (Silva et al. 2009). Oestrogen is known to play an important role in ovarian function and follicle growth (Zhang et al. 2017), and the biosynthesis of ovarian steroid hormones requires the action of various hydroxylases and aromatase enzymes. We observed that the mRNA expression of $3 \beta-H S D$ and $17 \beta$-HSD1 in the ovary of PEE foetal rats was significantly increased. However, the expression of $3 \beta-H S D$ was significantly reduced from 15.5 days after mating and was sustained until after birth under physiological conditions (Dutta et al. 2014).

In this study, the expression levels of steroidogenic enzymes in the PEE foetuses were abnormally activated, but no significant increase was found in the foetal serum $\mathrm{E}_{2}$ level. The cause might be that on the one hand, the expression of P450arom (a key enzyme for $\mathrm{E}_{2}$ synthesis) was not elevated; on the other hand, foetal hormones were from multiple sources, including local production, maternal blood circulation and placenta and interference in any part will affect the $\mathrm{E}_{2}$ level (Dutta et al. 2014). Furthermore, we found that the expression levels of IGF1, AKT2, 3 $\beta-H S D$ and P450arom were increased in a concentration-dependent manner with ethanol treatment, and the $\mathrm{E}_{2}$ level in the high concentration of ethanol group was increased in vitro. After IGF1 siRNA treatment, the protein expression of pAKT/AKT was decreased under ethanol, and the downstream P450arom mRNA level was relatively decreased, accompanied by a relative decrease in the $\mathrm{E}_{2}$ level. Because the KGN cell line is a useful cell type to explore steroidogenesis, growth and apoptosis of granulosa cells, it was used to verify the effects of maternal simazine exposure on the activity and proliferation of granulosa cells of offspring (Park et al. 2014). In the present study, although some limitations exist in the species and exposure window in the in vitro experiment, the interference of ethanol on the function of granulosa cells could also be validated preliminarily to a certain extent. These results suggest that the excessive activation of the IGF1 signalling pathway induced by PEE promotes the expression of steroidogenic enzymes, and the activated steroidal synthetic system might induce the potentially disordered endocrine environment in the ovary, likely affecting the physiological development of the foetal ovary. https://joe.bioscientifica.com

https://doi.org/10.1530/JOE-19-0063 (c) 2019 Society for Endocrinology Published by Bioscientifica Ltd.
Printed in Great Britain 


\section{Alterations of the IGF1 signalling pathway and steroidogenic enzymes are involved in ovarian development abnormalities in PEE female offspring after birth}

A comparative study of various POI animal models showed that the body weight gain rates of the model groups under some inducers were lower (Zhang et al. 2016). In the present study, the body weight gain rate of female PEE offspring rats at PW6 was significantly higher, and then gradually slowed down; at PW12, the body weight was significantly reduced, but the ovarian index was increased. Several studies have confirmed that IUGR offspring caused by adverse environment during pregnancy will have catch-up growth in the early postnatal period-that is, a state in which growth is accelerated due to nutritional status or environmental improvement after birth and is associated with increased levels of IGF1 in vivo (Jensen et al. 2015, Myrie et al. 2017). In the present study, the IGF1 signalling pathway was converted from the activated state at PW6 to relative inhibition at PW12. These results suggest that the changes in IGF1 signalling pathway expression are involved in the compensatory development in the early childhood of PEE offspring, and local development of ovary was faster than that of the whole body.

In recent years, many clinical studies have regarded the serum AMH level as a sensitive indicator of POI (Du et al. 2016). More primordial follicles will be recruited to growing follicles under a deficient AMH level, which will accelerate the depletion of the ovarian follicle pool; therefore, the POI women always have significantly lower AMH levels than healthy women (Kruszynska \& Slowinska-Srzednicka 2017). Our IHC results showed that the number of AMH-positive antral follicles in the adult PEE female offspring was reduced, indicating that the local AMH expression in the ovary was inhibited to some extent. However, the serum AMH levels did not decrease significantly as expected at this time, probably due to the limited number of small antral follicles that express AMH (Anderson 2012). Furthermore, ovarian granulosa cells are important for the survival of oocytes (Wang et al. 2017b). We observed that the thicknesses of ovarian granulosa cells in the PEE female offspring were continuously thinned from puberty to adulthood, and this phenomenon was also observed in other POI animal models (Zhang et al. 2016). Additionally, $\mathrm{E}_{2}$ is produced by follicle granulosa cells, promoting follicle development and the survival of granulosa cells by reducing apoptosis (Billig et al. 1993), and the IGF1 signalling pathway stimulates the production of $\mathrm{E}_{2}$ and increases the expression of P450arom mRNA in granulosa cells (Chabrolle et al. 2009, Mani et al. 2010). In this study, the atretic follicle ratio of PEE female offspring was increased significantly at PW12, while the serum $\mathrm{E}_{2}$ levels and expression of ovarian steroidogenic enzymes were decreased. These results suggest that the decreased function of ovarian steroidogenic enzymes in adulthood mediates the low oestrogen synthesis, which might be related to changes in the IGF1 signalling pathway, while the decreased $E_{2}$ level further affects the survival of granulosa cells and induces the thinning of the granulosa cell layer.

\section{HPO axis feedback regulates abnormal ovarian development in PEE female offspring}

Regulation of the hypothalamus-pituitary axis also plays an important regulatory role in ovarian development. During the intrauterine period, the function of the HPO axis is not fully established. The maturity of the female reproductive function initiates from puberty, and the HPO axis is fully established at this moment to activate puberty (Sliwowska et al. 2016). Animal studies have confirmed that PEE can change the development and function of the HPO axis in offspring, delay the initiation of puberty, reduce the feedback secretion of gonadotropin on $\mathrm{E}_{2}$ and lead to early estrous cycle disorder (Sliwowska et al. 2016). A disordered estrous cycle indicates that the normal

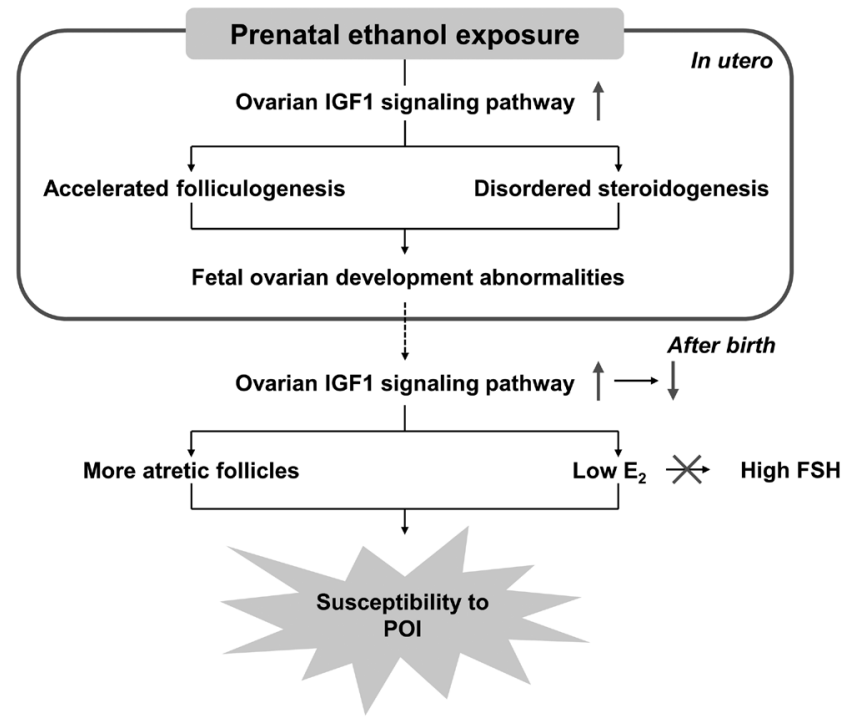

Figure 10

Intrauterine programming mechanism of susceptibility to premature ovarian insufficiency (POI) in adult female rat offspring induced by prenatal ethanol exposure. $\mathrm{E}_{2}$, oestradiol; FSH, follicle-stimulating hormone; IGF1, insulin-like growth factor 1. 
regulatory function state of the HPO axis is disturbed (Goldman et al. 2007), as observed in this study. Although the serum FSH level was significantly increased in adult PEE offspring, the serum $\mathrm{E}_{2}$ level did not increase, and Kiss1 and GnRH mRNA expression in the hypothalamus did not change significantly. Therefore, no feedback was observed at the hypothalamic level, indicating that negative feedback dysfunction occurred among the hypothalamus, pituitary and gonads, and the ovarian response to pituitary gonadotropin was impaired (Tsoulis et al. 2016) that, in turn, affected the normal reproductive endocrine function of the HPO axis. These results suggest that PEE can inhibit the establishment of the HPO axis function in the female offspring, indirectly enhancing the susceptibility to POI.

\section{Conclusion}

PEE could increase the susceptibility to adult POI in the female offspring rats, accompanied by abnormal ovarian structural and functional development. The mechanism may be related to over-activation of the intrauterine ovarian IGF1 signalling pathway and steroidal synthetase system induced by ethanol. These changes accelerate folliculogenesis, and affect the levels of steroid hormones, resulting in increased atretic follicles after birth (Fig. 10). This study provides some evidence to explore abnormal ovarian development and the intrauterine origin mechanism of POI in drinking during pregnancy, which has guiding significance to advocate the maintenance of healthy living habits in the gestational period.

\section{Supplementary data}

This is linked to the online version of the paper at https://doi.org/10.1530/ JOE-19-0063.

\section{Declaration of interest}

The authors declare that there is no conflict of interest that could be perceived as prejudicing the impartiality of the research reported.

\section{Funding}

This work was supported by grants from the National Natural Science Foundation of China (No. 81430089 to H W, 81571513 to J Y, 81671472 to D X, and 81673524 to $\mathrm{H}$ W), the National Key Research and Development Program of China (No. 2017YFC1001300 to H W, 2016 YFC1000600 and 2018 YFC1002804 to J Y).

\section{Author contribution statement}

$D X$ and $\mathrm{H} \mathrm{W}$ designed the experiments; $Y$ N, F L, G F, W Z and Y C carried out the experiments; $F \mathrm{~L}$ and $\mathrm{L} P$ prepared the experimental animals; $Y N$, $D X, J Y$ and $H W$ analysed the experimental results; $N Y$ and $D X$ wrote the manuscript and $F L, Y W$, and $G F$ revised the manuscript. All the work was performed under the guidance of $\mathrm{J}$ and $\mathrm{H} \mathrm{W}$.

\section{References}

Anderson RA 2012 What does anti-Mullerian hormone tell you about ovarian function? Clinical Endocrinology 77 652-655. (https://doi. org/10.1111/j.1365-2265.2012.04451.x)

Arendrup FS, Mazaud-Guittot S, Jegou B \& Kristensen DM 2018 EDC IMPACT: is exposure during pregnancy to acetaminophen/ paracetamol disrupting female reproductive development? Endocrine Connections 7 149-158. (https://doi.org/10.1530/EC-17-0298)

Bernstein LR, Mackenzie AC, Kraemer DC, Morley JE, Farr S, Chaffin CL \& Merchenthaler I 2014 Shortened estrous cycle length, increased FSH levels, FSH variance, oocyte spindle aberrations, and early declining fertility in aging senescence-accelerated mouse prone-8 (SAMP8) mice: concomitant characteristics of human midlife female reproductive aging. Endocrinology 155 2287-2300. (https://doi. org/10.1210/en.2013-2153)

Billig H, Furuta I \& Hsueh AJ 1993 Estrogens inhibit and androgens enhance ovarian granulosa cell apoptosis. Endocrinology 1332204 2212. (https://doi.org/10.1210/endo.133.5.8404672)

Chabrolle C, Tosca L, Rame C, Lecomte P, Royere D \& Dupont J 2009 Adiponectin increases insulin-like growth factor I-induced progesterone and estradiol secretion in human granulosa cells. Fertility and Sterility 92 1988-1996. (https://doi.org/10.1016/j. fertnstert.2008.09.008)

Chan KA, Jazwiec PA, Gohir W, Petrik JJ \& Sloboda DM 2018 Maternal nutrient restriction impairs young adult offspring ovarian signaling resulting in reproductive dysfunction and follicle loss. Biology of Reproduction 98 664-682. (https://doi.org/10.1093/biolre/ioy008)

Ciucci F, Putignano E, Baroncelli L, Landi S, Berardi N \& Maffei L 2007 Insulin-like growth factor 1 (IGF-1) mediates the effects of enriched environment (EE) on visual cortical development. PLOS ONE 2 e475. (https://doi.org/10.1371/journal.pone.0000475)

Cruz G, Fernandois D \& Paredes AH 2017 Ovarian function and reproductive senescence in the rat: role of ovarian sympathetic innervation. Reproduction 153 R59-R68. (https://doi.org/10.1530/ REP-16-0117)

de Bruin JP, Dorland M, Bruinse HW, Spliet W, Nikkels PG \& Te Velde ER 1998 Fetal growth retardation as a cause of impaired ovarian development. Early Human Development 51 39-46. (https://doi. org/10.1016/S0378-3782(97)00073-X)

Du DF, Li XL \& Zheng SH 2016 Expression of anti-Mullerian hormone in two rat models of polycystic ovary syndrome. Journal of Obstetrics and Gynaecology Research 42 1761-1767. (https://doi.org/10.1111/ jog.13118)

Dupont C, Cordier AG, Junien C, Mandon-Pepin B, Levy R \& ChavattePalmer P 2012 Maternal environment and the reproductive function of the offspring. Theriogenology 78 1405-1414. (https://doi. org/10.1016/j.theriogenology.2012.06.016)

Dutta S, Mark-Kappeler CJ, Hoyer PB \& Pepling ME 2014 The steroid hormone environment during primordial follicle formation in perinatal mouse ovaries. Biology of Reproduction 91 68. (https://doi. org/10.1095/biolreprod.114.119214)

ESHRE Guideline Group on POI, Webber L, Davies M, Anderson R, Bartlett J, Braat D, Cartwright B, Cifkova R, de Muinck KeizerSchrama S, Hogervorst E, et al. 2016 ESHRE Guideline: management https://joe.bioscientifica.com

https://doi.org/10.1530/JOE-19-0063 (c) 2019 Society for Endocrinology Published by Bioscientifica Ltd. Printed in Great Britain 
of women with premature ovarian insufficiency. Human Reproduction 31 926-937. (https://doi.org/10.1093/humrep/dew027)

Findlay JK, Hutt KJ, Hickey M \& Anderson RA 2015 How is the number of primordial follicles in the ovarian reserve established? Biology of Reproduction 93 111. (https://doi.org/10.1095/biolreprod.115.133652)

Gawalek M \& Sliwowska JH 2015 Neuronal basis of reproductive dysfunctions associated with diet and alcohol: from the womb to adulthood. Reproductive Biology 15 69-78. (https://doi.org/10.1016/j. repbio.2015.04.001)

Gohlke JM, Griffith WC \& Faustman EM 2005 A systems-based computational model for dose-response comparisons of two mode of action hypotheses for ethanol-induced neurodevelopmental toxicity. Toxicological Sciences 86 470-484. (https://doi.org/10.1093/toxsci/ kfi209)

Goldman JM, Murr AS \& Cooper RL 2007 The rodent estrous cycle: characterization of vaginal cytology and its utility in toxicological studies. Birth Defects Research: Part B, Developmental and Reproductive Toxicology 80 84-97. (https://doi.org/10.1002/bdrb.20106)

Guzman C, Garcia-Becerra R, Aguilar-Medina MA, Mendez I, MerchantLarios H \& Zambrano E 2014 Maternal protein restriction during pregnancy and/or lactation negatively affects follicular ovarian development and steroidogenesis in the prepubertal rat offspring. Archives of Medical Research 45 294-300. (https://doi.org/10.1016/j. arcmed.2014.05.005)

Hartmann BW, Kirchengast S, Albrecht A, Huber JC \& Soregi G 1997 Effect of hormone replacement therapy on growth hormone stimulation in women with premature ovarian failure. Fertility and Sterility 68 103-107. (https://doi.org/10.1016/s0015-0282(97)81483-5)

Huang H, Liu L, Li J, Zhu C, Xie X, Ao Y \& Wang H 2018 Autophagy as a compensation mechanism participates in ethanol-induced fetal adrenal dysfunction in female rats. Toxicology and Applied Pharmacology 345 36-47. (https://doi.org/10.1016/j.taap.2018.03.007)

Jensen RB, Juul A, Larsen T, Mortensen EL \& Greisen G 2015 Cognitive ability in adolescents born small for gestational age: associations with fetal growth velocity, head circumference and postnatal growth. Early Human Development 91 755-760. (https://doi.org/10.1016/j. earlhumdev.2015.08.014)

Khorram O, Keen-Rinehart E, Chuang TD, Ross MG \& Desai M 2015 Maternal undernutrition induces premature reproductive senescence in adult female rat offspring. Fertility and Sterility 103 291-298. (https://doi.org/10.1016/j.fertnstert.2014.09.026)

Kruszynska A \& Slowinska-Srzednicka J 2017 Anti-Mullerian hormone $(\mathrm{AMH})$ as a good predictor of time of menopause. Przeglad Menopauzalny 16 47-50. (https://doi.org/10.5114/pm.2017.68591)

Lv F, Wan Y, Chen Y, Pei L, Luo D, Fan G, Luo M, Xu D \& Wang H 2018 Prenatal dexamethasone exposure induced ovarian developmental toxicity and transgenerational effect in rat offspring. Endocrinology 159 1401-1415. (https://doi.org/10.1210/en.2018-00044)

Mani AM, Fenwick MA, Cheng Z, Sharma MK, Singh D \& Wathes DC 2010 IGF1 induces up-regulation of steroidogenic and apoptotic regulatory genes via activation of phosphatidylinositol-dependent kinase/AKT in bovine granulosa cells. Reproduction 139 139-151. (https://doi.org/10.1530/REP-09-0050)

May PA, Gossage JP, Brooke LE, Snell CL, Marais AS, Hendricks LS, Croxford JA \& Viljoen DL 2005 Maternal risk factors for fetal alcohol syndrome in the Western Cape Province of South Africa: a population-based study. American Journal of Public Health $\mathbf{9 5}$ 1190-1199. (https://doi.org/10.2105/AJPH.2003.037093)

Moyer B \& Hixon ML 2012 Reproductive effects in F1 adult females exposed in utero to moderate to high doses of mono-2ethylhexylphthalate (MEHP). Reproductive Toxicology 34 43-50. (https://doi.org/10.1016/j.reprotox.2012.02.006)

Myrie SB, McKnight LL, King JC, McGuire JJ, Van Vliet BN, Cheema SK \& Bertolo RF 2017 Intrauterine growth-restricted Yucatan miniature pigs experience early catch-up growth, leading to greater adiposity and impaired lipid metabolism as young adults. Applied Physiology,
Nutrition, and Metabolism 42 1322-1329. (https://doi.org/10.1139/ apnm-2017-0311)

Nykjaer C, Alwan NA, Greenwood DC, Simpson NA, Hay AW, White KL \& Cade JE 2014 Maternal alcohol intake prior to and during pregnancy and risk of adverse birth outcomes: evidence from a British cohort. Journal of Epidemiology and Community Health 68 542-549. (https://doi.org/10.1136/jech-2013-202934)

Ozcan P, Ficicioglu C, Yildirim ÖK, Ozkan F, Akkaya H \& Aslan İ 2015 Protective effect of resveratrol against oxidative damage to ovarian reserve in female Sprague-Dawley rats. Reproductive Biomedicine Online 31 404-410. (https://doi.org/10.1016/j.rbmo.2015.06.007)

Pantazis NJ, Dohrman DP, Luo J, Goodlett CR \& West JR 1992 Alcohol reduces the number of pheochromocytoma (PC12) cells in culture. Alcohol 9 171-180. (https://doi.org/10.1016/0741-8329(92)90048-F)

Park S, Kim S, Jin H, Lee K \& Bae J 2014 Impaired development of female mouse offspring maternally exposed to simazine. Environmental Toxicology and Pharmacology 38 845-851. (https://doi.org/10.1016/j. etap.2014.10.008)

Picut CA, Dixon D, Simons ML, Stump DG, Parker GA \& Remick AK 2015 Postnatal ovary development in the rat: morphologic study and correlation of morphology to neuroendocrine parameters. Toxicologic Pathology 43 343-353. (https://doi.org/10.1177/0192623314544380)

Saatcioglu HD, Cuevas I \& Castrillon DH 2016 Control of oocyte reawakening by kit. PLoS Genetics $\mathbf{1 2}$ e1006215. (https://doi. org/10.1371/journal.pgen.1006215)

Serrano Mujica LK, Bertolin K, Bridi A, Glanzner WG, Rissi VB, de Camargo FL, Zanella R, Prestes OD, Moresco RN, Antoniazzi AQ, et al. 2017 The impact of postnatal leuprolide acetate treatment on reproductive characteristics in a rodent model of polycystic ovary syndrome. Molecular and Cellular Endocrinology 442 125-133. (https:// doi.org/10.1016/j.mce.2016.12.015)

Shah JS, Sabouni R, Cayton Vaught KC, Owen CM, Albertini DF \& Segars JH 2018 Biomechanics and mechanical signaling in the ovary: a systematic review. Journal of Assisted Reproduction and Genetics $\mathbf{3 5}$ 1135-1148. (https://doi.org/10.1007/s10815-018-1180-y)

Shen L, Liu Z, Gong J, Zhang L, Wang L, Magdalou J, Chen L \& Wang H 2014 Prenatal ethanol exposure programs an increased susceptibility of non-alcoholic fatty liver disease in female adult offspring rats. Toxicology and Applied Pharmacology 274 263-273. (https://doi. org/10.1016/j.taap.2013.11.009)

Silva JR, Figueiredo JR \& van den Hurk R 2009 Involvement of growth hormone (GH) and insulin-like growth factor (IGF) system in ovarian folliculogenesis. Theriogenology 71 1193-1208. (https://doi org/10.1016/j.theriogenology.2008.12.015)

Sivakumar KK, Stanley JA, Arosh JA, Pepling ME, Burghardt RC \& Banu SK 2014 Prenatal exposure to chromium induces early reproductive senescence by increasing germ cell apoptosis and advancing germ cell cyst breakdown in the F1 offspring. Developmental Biology 388 22-34. (https://doi.org/10.1016/j.ydbio.2014.02.003)

Sliwowska JH, Comeau WL, Bodnar TS, Ellis L \& Weinberg J 2016 Prenatal alcohol exposure and pair feeding differentially impact puberty and reproductive development in female rats: role of the kisspeptin system. Alcoholism, Clinical and Experimental Research 40 2368-2376. (https://doi.org/10.1111/acer.13233)

Spohr HL, Willms J \& Steinhausen HC 1993 Prenatal alcohol exposure and long-term developmental consequences. Lancet 341 907-910. (https://doi.org/10.1016/0140-6736(93)91207-3)

Srivastava VK, Hiney JK \& Dees WL 1999 Effects of ethanol on the intraovarian insulin-like growth factor-1 system in the prepubertal rat. Alcoholism, Clinical and Experimental Research 23 293-300. (https://doi.org/10.1111/j.1530-0277.1999.tb04113.x)

Srivastava VK, Hiney JK, Mattison JA, Bartke A \& Dees WL 2007 The alcohol-induced suppression of ovarian insulin-like growth factor-1 gene transcription is independent of growth hormone and its receptor. Alcoholism, Clinical and Experimental Research 31 880-886. (https://doi.org/10.1111/j.1530-0277.2007.00368.x) https://joe.bioscientifica.com

https://doi.org/10.1530/JOE-19-0063 (c) 2019 Society for Endocrinology Published by Bioscientifica Ltd. Printed in Great Britain 
Stubbs SA, Webber LJ, Stark J, Rice S, Margara R, Lavery S, Trew GH, Hardy K \& Franks S 2013 Role of insulin-like growth factors in initiation of follicle growth in normal and polycystic human ovaries. Journal of Clinical Endocrinology and Metabolism 98 3298-3305. (https://doi.org/10.1210/jc.2013-1378)

Tsoulis MW, Chang PE, Moore CJ, Chan KA, Gohir W, Petrik JJ, Vickers MH, Connor KL \& Sloboda DM 2016 Maternal high-fat dietinduced loss of fetal oocytes is associated with compromised follicle growth in adult rat offspring. Biology of Reproduction 94 94. (https:// doi.org/10.1095/biolreprod.115.135004)

Vabre P, Gatimel N, Moreau J, Gayrard V, Picard-Hagen N, Parinaud J \& Leandri RD 2017 Environmental pollutants, a possible etiology for premature ovarian insufficiency: a narrative review of animal and human data. Environmental Health 16 37. (https://doi.org/10.1186/ s12940-017-0242-4)

Wang C, Zhang R, Zhou L, He J, Huang Q, Siyal FA, Zhang L, Zhong X \& Wang T 2017a Intrauterine growth retardation promotes fetal intestinal autophagy in rats via the mechanistic target of rapamycin pathway. Journal of Reproduction and Development 63 547-554. (https:// doi.org/10.1262/jrd.2017-050)

Wang C, Zhou B \& Xia G $2017 b$ Mechanisms controlling germline cyst breakdown and primordial follicle formation. Cellular and Molecular Life Sciences 74 2547-2566. (https://doi.org/10.1007/s00018-0172480-6)

Wilson ME \& Handa RJ 1997 Gonadotropin secretion in infantile rats exposed to ethanol in utero. Alcohol 14 497-501. (https://doi. org/10.1016/S0741-8329(97)00037-2)

Yan X, Yuan C, Zhao N, Cui Y \& Liu J 2014 Prenatal androgen excess enhances stimulation of the GNRH pulse in pubertal female rats.
Journal of Endocrinology 222 73-85. (https://doi.org/10.1530/JOE-140021)

Yang CY, Yu ML, Guo HR, Lai TJ, Hsu CC, Lambert G \& Guo YL 2005 The endocrine and reproductive function of the female Yucheng adolescents prenatally exposed to PCbs/PCDFs. Chemosphere $\mathbf{6 1}$ 355-360. (https://doi.org/10.1016/j.chemosphere.2005.02.089)

Yu L, Zhou J, Zhang G, Huang W, Pei L, Lv F, Zhang Y, Zhang W \& Wang H 2018 cAMP/PKA/EGR1 signaling mediates the molecular mechanism of ethanol-induced inhibition of placental 11beta-HSD2 expression. Toxicology and Applied Pharmacology 352 77-86. (https:// doi.org/10.1016/j.taap.2018.05.029)

Zhang XF, Zhang T, Han Z, Liu JC, Liu YP, Ma JY, Li L \& Shen W 2015 Transgenerational inheritance of ovarian development deficiency induced by maternal diethylhexyl phthalate exposure. Reproduction, Fertility, and Development 27 1213-1221. (https://doi.org/10.1071/ RD14113)

Zhang T, Yan D, Yang Y, Ma A, Li L, Wang Z, Pan Q \& Sun Z 2016 The comparison of animal models for premature ovarian failure established by several different source of inducers. Regulatory Toxicology and Pharmacology 81 223-232. (https://doi.org/10.1016/j. yrtph.2016.09.002)

Zhang H, Taya K, Nagaoka K, Yoshida M \& Watanabe G 2017 Neonatal exposure to 17alpha-ethynyl estradiol (EE) disrupts follicle development and reproductive hormone profiles in female rats. Toxicology Letters 276 92-99. (https://doi.org/10.1016/j.toxlet.2017.05.014)

Zheng W, Nagaraju G, Liu Z \& Liu K 2012 Functional roles of the phosphatidylinositol 3-kinases (PI3Ks) signaling in the mammalian ovary. Molecular and Cellular Endocrinology 356 24-30. (https://doi. org/10.1016/j.mce.2011.05.027)

Received in final form 14 June 2019

Accepted 25 July 2019

Accepted Preprint published online 25 July 2019 (c) 2019 Society for Endocrinology Published by Bioscientifica Ltd.
Printed in Great Britain 